\title{
Reactions with 5-Arylmethylene-2-phenylhydrazono-4-thiazolidinones A Novel Synthesis of Thiazolo[2,3-c]triazine Derivatives
}

\author{
Sanaa O. Abd Allah*, Sherif M. Fahmy, and Hamed A. Ead \\ Department of Chemistry, Faculty of Science, University of Cairo, Giza, Egypt \\ Z. Naturforsch. 39b, 390-392 (1984); received June 7, 1983 \\ Alkylation, Alkylcyclization, Cyanoethylation, Acetylation
}

The 5-arylmethylene derivatives of 2-phenylhydrazono-4-thiazolidinone (1) reacted with phenacyl bromide and with ethyl bromoacetate to yield the thiazolo[2,3-c]triazine derivatives (3) and (4). The reaction of $\mathbf{1}$ with carbon disulphide in alkaline solution afforded the bis $\left(\mathrm{N}^{1}\right.$ 2-phenylhydrazono-4-thiazolidinone)thiocarbonyl derivatives (6). Cyanoethylation of $\mathbf{1}$ afforded the $\mathrm{N}^{1}-\beta$-cyanoethylphenylhydrazono derivatives (7).

In extension of our program directed for the development of new simple routes for the synthesis of fused thiazolo-triazoles $[1,2]$ we have investigated the reaction of 5-arylmethylene-2-phenylhydrazono4-thiazolidinones [3] (1a) and (1) b) with phenacyl bromide and with ethyl bromoacetate aiming to obtain new thiazolo-triazines of probable biological activities.

Thus, subjecting $\mathbf{1} \mathbf{a}$ or $\mathbf{1} \mathbf{b}$ to the action of phenacyl bromide in dimethylformamide effected alkylation on the exocyclic $\mathrm{N}^{1}$-phenylhydrazono moiety to give the $\mathrm{N}^{1}$-phenacylphenylhydrazono derivatives $\mathbf{2} \mathbf{a}$ and $\mathbf{2 b}$, respectively. The structure assigned for $\mathbf{2}$ was inferred from analytical and IR data; besides, ethanolhydrochloric acid hydrolysis of $\mathbf{2}$ a afforded 5phenylmethylene-2,4-thiazolidinedione [4]. On the other hand, when the reaction between $\mathbf{1} \mathbf{a}$ or $\mathbf{1} \mathbf{b}$ and phenacyl bromide was carried out in refluxing ethanol containing few drops of triethylamine the thiazolo[2,3-c]-1,2,4-triazine derivative $\mathbf{3} \mathbf{a}$ or $\mathbf{3} \mathbf{b}$ was obtained. The structure of $\mathbf{3} \mathbf{a}$ or $\mathbf{3} \mathbf{b}$ was assigned based on elemental and IR data; besides its synthesis via another route, by refluxing compound $\mathbf{2} \mathbf{a}$ and/or 2b in ethanol containing catalytic amounts of triethylamine.

When equimolecular amounts of $\mathbf{1} \mathbf{a}$ or $\mathbf{1} \mathbf{b}$ and ethyl bromoacetate were allowed to react in dimethylformamide the thiazolo[2,3-c]-1,2,4-triazinone derivative $\mathbf{4} \mathbf{a}$ or $\mathbf{4} \mathbf{b}$ was obtained. The structure of $\mathbf{4}$ was assigned based on elemental and IR data; besides ethanolhydrochloric acid hydrolysis of $\mathbf{4} \mathbf{a}$ to afford 5-phenylmethylene-2,4-thiazolidinedione [4]. The

* Reprint requests to Dr. S. Abd Allah. $0340-5087 / 84 / 0300-0390 /$ \$ $01.00 / 0$

reaction of an ethanolic solution of $\mathbf{1 a}$ or $\mathbf{1 b}$ with carbon disulphide in alkaline medium was carried out aiming to obtain the thiazolo-triazolthione derivative 5, but instead, the bis $\left(\mathrm{N}^{1}-2\right.$-phenylhydrazono-4-thiazolidinone) thiocarbonyl derivative $\mathbf{6 a}$ or $\mathbf{6} \mathbf{b}$ was obtained. The structure of $\mathbf{6}$ was infer-

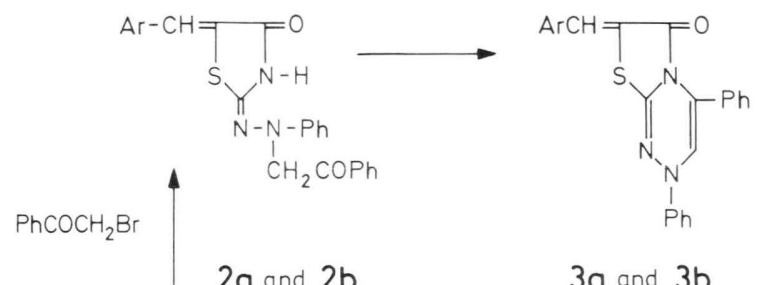

$2 a$ and $2 b \quad 3 a$ and $3 b$

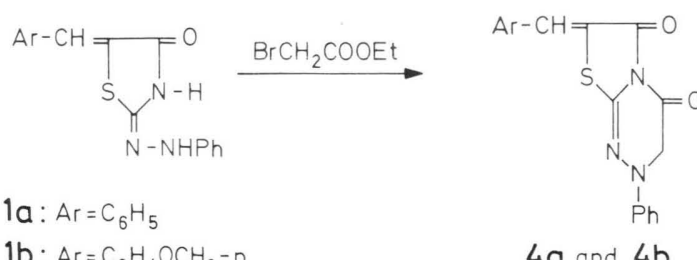

$$
\text { 1b: } \mathrm{Ar}=\mathrm{C}_{6} \mathrm{H}_{4} \mathrm{OCH}_{3}-\mathrm{p} \quad 4 \mathrm{a} \text { and } 4 \mathrm{~b}
$$

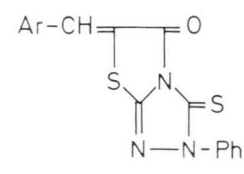

5

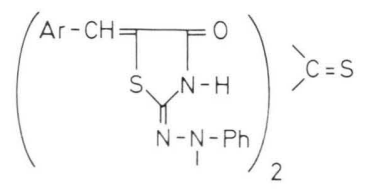

$6 a$ and $6 b$

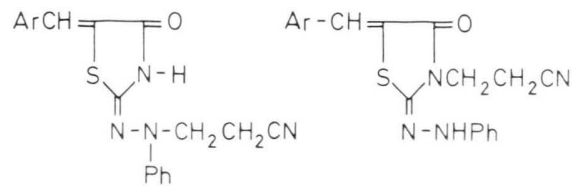

$7 a$ and $7 b$<smiles>CCC1SC(=NNC(C)=O)NC1=O</smiles>

$9 a$ and $9 b$ 
red from analytical and IR data; besides the hydrolysis of $\mathbf{6 a}$ to afford 5-phenylmethylene-2,4thiazolidinedione.

The reaction of $\mathbf{1}$ with acrylonitrile was also investigated. Thus, treatment of $\mathbf{1 a}$ or $\mathbf{1 b}$ with excess amount of acrylonitrile in aqueous pyridine afforded a 1:1 adduct as inferred from analytical data. Two structures $\mathbf{7}$ and $\mathbf{8}$ were considered for the adduct as they both agreed with the ${ }^{1} \mathrm{H}$ NMR and IR data. Structure $\mathbf{8}$ was ruled out based on the ethanolhydrochloric acid hydrolysis of the adducts to afford the corresponding 5-arylmethylene-2,4-thiazolidinedione.

The reaction of $\mathbf{1} \mathbf{a}$ or $\mathbf{1} \mathbf{b}$ with acetic anhydride afforded the 2-N $\mathrm{N}^{1}$-acetylphenylhydrazono-4-thiazolidinone derivative $\mathbf{9 a}$ or $\mathbf{9 b}$ as established from analytical and IR data. Besides, an authentic sample for 9 a was obtained via the reaction between $\mathrm{N}^{1}$ acetylphenylhydrazine hydrochloride [5] and 5phenylmethylene-2-thioxo-4-thiazolidinone [6].

\section{Experimental}

All melting points are uncorrected. IR spectra were obtained as a $\mathrm{KBr}$ disc with a Py-Unicam SP 1100 spectrophotometer. ${ }^{1} \mathrm{H}$ NMR spectra were ob- tained on a Varian A-60 spectrometer in DMSO- $\mathrm{d}_{6}$, using TMS as internal standard and chemical shift are expressed as $\delta$ ppm.

\section{5-Arylmethylene-2- $N^{1}$-phenacylphenylhydrazono- 4-thiazolidinones $\mathbf{2} \mathbf{a}$ and $\mathbf{2} \mathbf{b}$.}

To a solution of each of $\mathbf{1} \mathbf{a}$ or $\mathbf{1 b}(0.01 \mathrm{~mol})$ in $20 \mathrm{ml}$ of dimethylformamide was added an equimolecular amount of phenacyl bromide. The reaction mixture was heated on a water bath for $30 \mathrm{~min}$ and then allowed to cool. The solid product obtained on dilution with water was filtered off and crystallised from ethanol. The yellow coloured products $\mathbf{2} \mathbf{a}$ and $\mathbf{2} \mathbf{b}$ are listed in Table I. The IR spectrum of $\mathbf{2}$ a showed absorption at $3300 \mathrm{~cm}^{-1}$ (NH), $1710 \mathrm{~cm}^{-1}$ (phenacyl CO) and $1680 \mathrm{~cm}^{-1}$ (ring CO).

Thiazolo[2,3-c]-1,2,4-triazine derivatives $\mathbf{3 a}$ and $\mathbf{3 b}$.

A solution of equimolecular amounts (0.01 mol) of each of $\mathbf{1 a}$ or $\mathbf{1 b}$ and phenacyl bromide in $100 \mathrm{ml}$ of ethanol containing few drops of triethylamine was heated under reflux for $5 \mathrm{~h}$ and then allowed to cool. The solid product so obtained was filtered off and crystallised from ethanol. The yellow coloured products $\mathbf{3} \mathbf{a}$ and $\mathbf{3 b}$ are listed in Table I. The IR spectrum of $\mathbf{3 a}$ showed absorption at $1690 \mathrm{~cm}^{-1}$ (ring $\mathrm{CO})$ and $1620 \mathrm{~cm}^{-1}(\mathrm{C}=\mathrm{N})$.

\begin{tabular}{|c|c|c|c|c|c|c|c|}
\hline \multirow{2}{*}{$\begin{array}{l}\text { Com- } \\
\text { pound }\end{array}$} & \multirow{2}{*}{$\begin{array}{l}\text { m.p. } \\
\left({ }^{\circ} \mathrm{C}\right)\end{array}$} & \multirow{2}{*}{$\begin{array}{l}\text { Yield } \\
(\%)\end{array}$} & \multirow{2}{*}{$\begin{array}{l}\text { Formula } \\
\text { (mol.wt.) }\end{array}$} & \multicolumn{2}{|c|}{ Analysis } & \multicolumn{2}{|c|}{ Calcd/Found } \\
\hline & & & & $\mathrm{C}$ & $\mathrm{H}$ & $\mathrm{N}$ & $\mathrm{S}$ \\
\hline \multirow[t]{2}{*}{$2 \mathbf{a}$} & \multirow[t]{2}{*}{165} & \multirow[t]{2}{*}{55} & $\mathrm{C}_{24} \mathrm{H}_{19} \mathrm{~N}_{3} \mathrm{O}_{2} \mathrm{~S}$ & 69.72 & 4.63 & 10.16 & 7.74 \\
\hline & & & 413.4 & 69.63 & 4.61 & 10.11 & 7.70 \\
\hline \multirow[t]{2}{*}{$2 \mathbf{b}$} & \multirow[t]{2}{*}{176} & \multirow[t]{2}{*}{50} & $\mathrm{C}_{25} \mathrm{H}_{21} \mathrm{~N}_{3} \mathrm{O}_{3} \mathrm{~S}$ & 67.71 & 4.77 & 9.48 & 7.21 \\
\hline & & & 443.4 & 67.83 & 4.72 & 9.50 & 7.17 \\
\hline \multirow[t]{2}{*}{$3 \mathbf{a}$} & \multirow[t]{2}{*}{185} & \multirow[t]{2}{*}{60} & $\mathrm{C}_{24} \mathrm{H}_{17} \mathrm{~N}_{3} \mathrm{OS}$ & 72.90 & 4.33 & 10.63 & 8.09 \\
\hline & & & 395.4 & 73.01 & 4.29 & 10.83 & 8.11 \\
\hline \multirow[t]{2}{*}{$3 \mathbf{b}$} & \multirow[t]{2}{*}{198} & \multirow[t]{2}{*}{60} & $\mathrm{C}_{25} \mathrm{H}_{19} \mathrm{~N}_{3} \mathrm{O}_{2} \mathrm{~S}$ & 70.58 & 4.50 & 9.88 & 7.52 \\
\hline & & & 425.4 & 70.65 & 4.50 & 9.80 & 7.60 \\
\hline \multirow[t]{2}{*}{$4 a$} & \multirow[t]{2}{*}{215} & \multirow[t]{2}{*}{70} & $\mathrm{C}_{18} \mathrm{H}_{13} \mathrm{~N}_{3} \mathrm{O}_{2} \mathrm{~S}$ & 64.47 & 3.91 & 12.53 & 9.54 \\
\hline & & & 335.3 & 64.80 & 3.90 & 12.71 & 9.61 \\
\hline \multirow[t]{2}{*}{$4 b$} & \multirow[t]{2}{*}{244} & \multirow[t]{2}{*}{75} & $\mathrm{C}_{19} \mathrm{H}_{15} \mathrm{~N}_{3} \mathrm{O}_{3} \mathrm{~S}$ & 62.46 & 4.14 & 11.50 & 8.76 \\
\hline & & & 365.3 & 62.66 & 4.09 & 11.62 & 8.91 \\
\hline \multirow[t]{2}{*}{$6 a$} & \multirow[t]{2}{*}{190} & \multirow[t]{2}{*}{60} & $\mathrm{C}_{33} \mathrm{H}_{24} \mathrm{~N}_{6} \mathrm{O}_{2} \mathrm{~S}_{3}$ & 62.65 & 3.82 & 13.29 & 15.17 \\
\hline & & & 632.6 & 62.54 & 3.85 & 13.09 & 15.33 \\
\hline \multirow[t]{2}{*}{$6 b$} & \multirow[t]{2}{*}{222} & \multirow[t]{2}{*}{62} & $\mathrm{C}_{35} \mathrm{H}_{28} \mathrm{~N}_{6} \mathrm{O}_{4} \mathrm{~S}_{3}$ & 60.69 & 4.05 & 12.14 & 13.87 \\
\hline & & & 692.0 & 60.81 & 4.00 & 12.00 & 14.01 \\
\hline \multirow[t]{2}{*}{$7 a$} & \multirow[t]{2}{*}{176} & 80 & $\mathrm{C}_{19} \mathrm{H}_{16} \mathrm{~N}_{4} \mathrm{OS}$ & 65.51 & 4.63 & 16.08 & 9.18 \\
\hline & & & 348.3 & 65.55 & 4.55 & 16.30 & 8.99 \\
\hline $7 b$ & 190 & 80 & $\mathrm{C}_{20} \mathrm{H}_{18} \mathrm{~N}_{4} \mathrm{O}_{2} \mathrm{~S}$ & 63.48 & 4.80 & 14.81 & 8.45 \\
\hline & & & 378.4 & 63.49 & 4.91 & 14.93 & 8.60 \\
\hline $9 \mathbf{a}$ & 185 & 55 & $\mathrm{C}_{18} \mathrm{H}_{15} \mathrm{~N}_{3} \mathrm{O}_{2} \mathrm{~S}$ & 64.09 & 4.48 & 12.46 & 9.48 \\
\hline & & & 337.3 & 64.10 & 4.51 & 12.60 & 9.41 \\
\hline $9 b$ & 188 & 50 & $\mathrm{C}_{19} \mathrm{H}_{17} \mathrm{~N}_{3} \mathrm{O}_{3} \mathrm{~S}$ & 62.12 & 4.66 & 11.44 & 8.71 \\
\hline & & & 367.3 & 61.91 & 4.70 & 11.70 & 8.50 \\
\hline
\end{tabular}

Table I. Analytical data for compounds 2-9. 
Cyclization of $\mathbf{2} \mathbf{a}$ or $\mathbf{2} \mathbf{b}$ to afford $\mathbf{3} \mathbf{a}$ or $\mathbf{3} \mathbf{b}$.

A solution of $\mathbf{2} \mathbf{a}$ or $\mathbf{2} \mathbf{b}(1.0 \mathrm{~g})$ in $50 \mathrm{ml}$ of ethanol containing few drops of triethylamine was refluxed for $5 \mathrm{~h}$ then allowed to cool. The solid product so obtained was filtered off and crystallised from ethanol to afford $\mathbf{3 a}$ or $\mathbf{3 b}$ respectively (m.p. and mixed m.p.).

\section{Thiazolo[2,3-c]-1,2,4-triazinone derivatives}

\section{$\mathbf{4 a}$ and $\mathbf{4 b}$.}

A solution of $\mathbf{1 a}$ or $\mathbf{1 b}(0.01 \mathrm{~mol})$ in $30 \mathrm{ml}$ of dimethylformamide was treated with an equimolecular amount of ethyl bromoacetate. The reaction mixture was heated on a water bath for $4 \mathrm{~h}$ then allowed to cool and diluted with water. The solid product so obtained was filtered off and crystallised from ethanol-acetone mixture. Compounds $\mathbf{4 a}$ and $\mathbf{4} \mathbf{b}$ are orange coloured and listed in Table I. The IR spectrum of $4 \mathbf{a}$ showed absorption at 1730 and $1680 \mathrm{~cm}^{-1}$ (CO) and $1620 \mathrm{~cm}^{-1}(\mathrm{C}=\mathrm{N})$. The ${ }^{1} \mathrm{H}$ NMR spectrum of $\mathbf{4 a}$ showed signals at $7.8-6.8(\mathrm{~m}, 11 \mathrm{H}, 2 \mathrm{Ph}$ and vinylic proton) and $3.9\left(\mathrm{~s}, 2 \mathrm{H}, \mathrm{CO}-\mathrm{CH}_{2}\right)$.

\section{Bis (5-arylmethylene-2-phenylhydrazono-}

4-thiazolidinone) thiocarbonyl derivatives $\mathbf{6} \mathbf{a}$ and $\mathbf{6 b}$.

To a $100 \mathrm{ml}$ solution of ethanolic potassium hydroxide $(0.1 \mathbf{M})$ was added $0.01 \mathrm{~mol}$ of $\mathbf{1} \mathbf{a}$ or $\mathbf{1} \mathbf{b}$ and $10 \mathrm{ml}$ of carbon disulphide. The reaction mixture was refluxed for $8 \mathrm{~h}$ then allowed to cool. The solid product obtained after treatment with acetic acid was collected by filteration and crystallised from ethanol. Compounds $\mathbf{6 a}$ and $\mathbf{6 b}$ are orange coloured and are listed in Table I. The IR spectrum of $\mathbf{6} \mathbf{a}$ showed absorption at $3300 \mathrm{~cm}^{-1}(\mathrm{NH})$ and $1680 \mathrm{~cm}^{-1}$ (ring $\mathrm{CO})$.

5-Arylmethylene-2- $N^{I}-\beta$-cyanoethylphenylhydrazono4-thiazolidinones $\mathbf{7 a}$ and $\mathbf{7} \mathbf{b}$.

To a solution of each of $\mathbf{1} \mathbf{a}$ or $\mathbf{1} \mathbf{b}(0.01 \mathrm{~mol})$ in aqueous pyridine $(30 \mathrm{ml}$ pyridine and $10 \mathrm{ml}$ water $)$ was added excess of acrylonitrile and the reaction mixture was refluxed for $5 \mathrm{~h}$. The solid product obtained after evaporation of pyridine was filtered off and crystallised from ethanol. Compounds $\mathbf{7 a}$ and $\mathbf{7 b}$ are yellow coloured and are listed in Table I. The IR spectrum of 7a showed absorption at $3200 \mathrm{~cm}^{-1}$ (NH), $2220 \mathrm{~cm}^{-1}(\mathrm{C} \equiv \mathrm{N})$ and $1680 \mathrm{~cm}^{-1}$ (ring CO). The ${ }^{1} \mathrm{H}$ NMR spectrum of $\mathbf{7}$ a showed signals at 9.2 $(\mathrm{s}, 1 \mathrm{H}, \mathrm{NH}), 7.8(\mathrm{~s}, 1 \mathrm{H}, \mathrm{Ph}-\mathrm{CH}=\mathrm{C}), 7.6-6.8(\mathrm{~m}$, $10 \mathrm{H}, 2 \mathrm{Ph}), 3.2\left(\mathrm{t}, 2 \mathrm{H}, \mathrm{CH}_{2}-\overline{\mathrm{CH}}_{2} \mathrm{CN}\right)$ and $2.9(\mathrm{t}$, $2 \mathrm{H}, \mathrm{CH}_{2}-\mathrm{CH}_{2}-\mathrm{CN}$ ).

\section{5-Arylmethylene-2- $N^{l}$-acetylphenylhydrazono- 4-thiazolidinones $\mathbf{9 a}$ and $\mathbf{9 b}$.}

A suspension of $\mathbf{1} \mathbf{a}$ or $\mathbf{1 b}(2.0 \mathrm{~g})$ in acetic anhydride $(30 \mathrm{ml})$ was heated on a water bath for $15 \mathrm{~min}$. The reaction mixture was poured in water and the solid so obtained was filtered off. Compounds $9 \mathbf{a}$ and $\mathbf{9 b}$ formed yellow crystals from ethanol and are listed in Table I. The IR spectrum of $\mathbf{9 a}$ showed absorption at $3180 \mathrm{~cm}^{-1}(\mathrm{NH})$, broad absorption at $1690 \mathrm{~cm}^{-1}$ (amide and ring CO).

\section{5-Phenylmethylene-2- $N^{l}$-acetylphenylhydrazono- 4-thiazolidinone $\mathbf{9 a}$.}

An equimolecular amount $(0.01 \mathrm{~mol})$ of $\mathrm{N}^{1}$-acetylphenylhydrazine hydrochloride and 5-phenylmethylene-2-thioxo-4-thiazolidinone in $50 \mathrm{ml}$ of ethanol containing anhydrous sodium acetate $(1.0 \mathrm{~g})$ was refluxed for $5 \mathrm{~h}$. The reaction mixture was allowed to cool, the solid so obtained was filtered off, washed with water and crystallised from ethanol to afford $\mathbf{9 a}$ (m.p. and mixed m.p.).

\section{Action of ethanolic-hydrochloric acid mixture on} $2 \mathbf{a}, 4 \mathbf{a}, 6 \mathbf{a}$ and $7 \mathbf{a}$.

A solution of each of $\mathbf{2 a}, \mathbf{4} \mathbf{a}, \mathbf{6} \mathbf{a}$ or $\mathbf{7 a}(1.0 \mathrm{~g})$ in a mixture of ethanol $(20 \mathrm{ml})$ and hydrochloric acid $(4 \mathrm{ml})$ was refluxed for $2 \mathrm{~h}$ then allowed to cool and diluted with water. The solid product so obtained was crystallised from ethanol, m.p. $225^{\circ}$, proved to be identical (m.p. and mixed m.p.) with 5-phenylmethylene-2,4-thiazolidinedione.
[1] N. A. Kassab, S. O. Abd Allah, and H. A. Ead, Z. Naturforsch. 31 b, 380 (1976).

[2] N. A. Kassab, S. O. Abd Allah, and H. A. Ead, Z. Naturforsch. 31b, 853 (1976).

[3] H. Taniyama and T. Yusa, J. Pharm. Soc. Jpn. 75, 5 (1955).
[4] D. Libermann, J. Himbert, and L. Hengl, Bull. Soc. Chim. Fr. 1948, 1120.

[5] H. Yamamoto, J. Org. Chem. 32, 3693 (1967).

[6] A. Mackie and A. L. Misra, J. Chem. Soc. 1954, 3919. 